\title{
Ebooks: the learning and teaching perspective
}

\author{
Suzanne Enright \\ University of Westminster
}

Ebooks are here to stay and have "come of age" as a fully accepted format for publishers, readers and libraries in the library and education sectors ${ }^{1}$. Ebooks (that is to say, electronic versions of academic books, textbooks, reference books, scholarly monographs, annuals and other "one-off" publications) are recognised as a strategic element for UK higher education (HE) library services, and their use as a tool to better serve the needs of our users remains a hot topic.

The key drivers pushing the University of Westminster to strengthen the digital aspects of our service (with the usual caveats about availability, price and appropriateness) are: strategic imperatives within the institution, changes to user behaviour and changes to the external environment, including the publishing model.

\section{Context}

Digital collections are a growing component of library services and the wider digital library development. The various drivers for the digital future

${ }^{1}$ Ebooks and Econtent 2014: Beyond Ebooks at University College London. https://www.ucl. ac.uk/dis/conferences/ebooks

How to cite this book chapter:

Enright, S. 2014. Ebooks: the learning and teaching perspective. In: Woodward, H. (ed.) Ebooks in Education: Realising the Vision. Pp. 21-33. London: Ubiquity Press. DOI: http://dx.doi.org/10.5334/bal.d 
of the book (or monograph) as a component of today's academic publishing landscape, the benefits and barriers for universities - locally, nationally and internationally - have been articulated variously and often. There has been a plethora of research, surveys and conferences devoted to the wide ranging world of ebooks, and I do not intend to examine them here. However, I will highlight key aspects of today's environment that I think are of especial interest to library service designers and providers.

Three recent studies, all from the USA in 2013, contextualise today's environment around delivery of digital services: firstly, there is OCLC's report Meeting the e-resources challenge on the effective management, access and delivery of e-collections for HE libraries ${ }^{2}$. It presents case studies of experiences structured around key tasks in the e-resource management workflow, including: selection, acquisition, describing, discovery, access and renewal of licensed content within libraries' electronic collections.

Secondly, there is the ECAR Study of Undergraduate Students and $I^{3}$ in which Educause collaborated with more than 250 USA HE institutions to collect responses from more than 112,000 undergraduate students about their technology experiences and expectations, and which explores the ways in which new, better, or more technology can impact students' relationship with information technology. It found the cost of textbooks was the most important value factor for students to use ebooks or e-textbooks, but a need for portability and availability outweighs that. As mentioned also in the context of my institution below, unfortunately the user experience is frustrating given complex platforms and incompatible devices.

Lastly, the Ithaka S+R US Library Survey ${ }^{4}$ examines how the leaders of academic libraries are approaching systemic changes in their environment and the opportunities and constraints they face in leading their organisations. From a collections standpoint, it found that spend on ebooks hadn't really increased since 2010, and yet its Faculty Survey (2012) found more than half of faculty members assert that ebooks play an important role in research and teaching.

\section{Local context at the University of Westminster}

\section{Our ebook collections}

At time of writing (Spring 2014) the University of Westminster spends around $70 \%$ of our materials budget on electronic content ( $£ 330.3 \mathrm{~K}$ in $2012 / 13$ ). Our digital library collection includes nearly 87,000 ejournals, 330,000 ebooks and over 140 databases; these generate around 3 million electronic usages

\footnotetext{
2 http://www.oclc.org/en-UK/publications/newsletters/enews/2013/36/02.html

${ }^{3}$ Educause Centre for Applied Research (ECAR) http://www.educause.edu/library/resources/ecar-study-undergraduate-students-and-information-technology-2013

${ }^{4}$ http://sr.ithaka.org/research-publications
} 


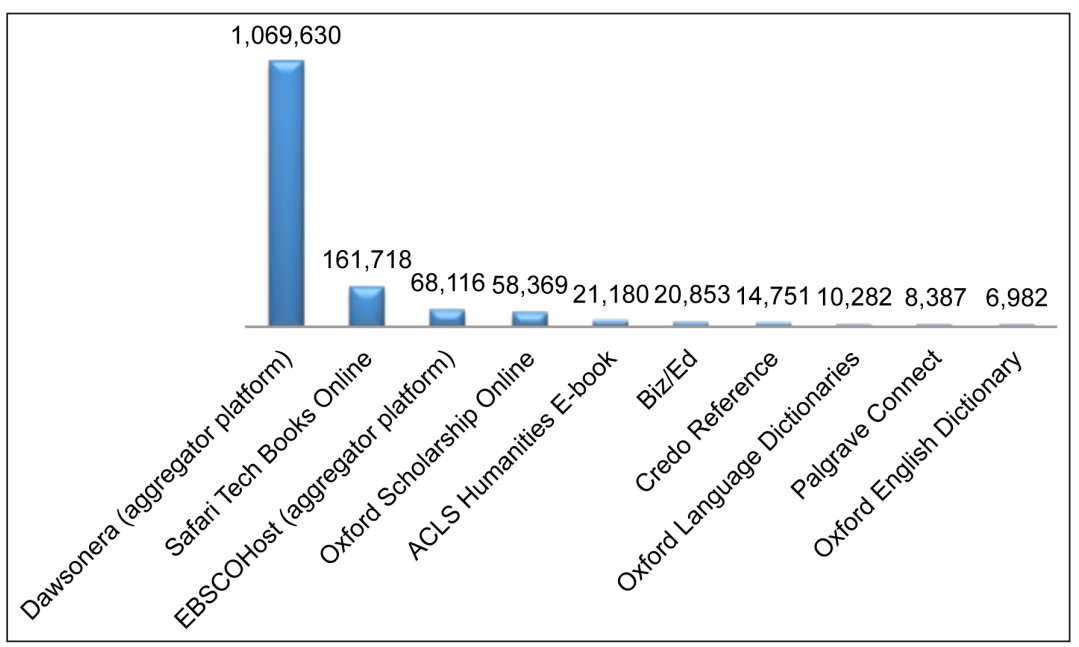

Figure 1: Top ten ebook resources - usage 2012-13.

annually. Access is these is split across about 1 million journal articles, 1.5 million ebook sections and 500,000 database searches, making this one of our key delivery areas. The ebooks we provide are, unsurprisingly, a mix of purchased, subscribed and open access (OA) including nearly twenty ebook collections. Notwithstanding the availability of the vast resource that is the Jisc Historic Books collection, the majority of our usage comes from single ebook purchases (course textbooks) which have been selected by the library, by our academics and through a Patron Driven Acquisition (PDA) pilot, and which are available through aggregator platforms such as Dawsonera, Safari Tech and EBSCOHost. The most popular collections support our faculties of Business, Science and Technology, Social Sciences \& Humanities, and Law, as well as multidisciplinary reference (see Figure 1). Within the institution, strategies for ebook management rely on relationships with the academic community to support targeted and strategic collection development around high profile, high impact content such as one-off ebook, ebook collection and course text purchases; all purchases must be in support of strategies for learning and teaching, and research.

\section{Ebook discovery and promotion}

The integrated management and discovery of the digital collection is through the Ex Libris suite, with its Primo service badged for our users as LibrarySearch. During 2012/13 we logged over 650,700 physical visits to our libraries (we record visits to three out of four libraries) and made nearly 685,000 loans. This compares to about 6 million electronic visits (about 3m ejournal/ebook and database and about $3 \mathrm{~m}$ LibrarySearch sessions). We ran a small pilot on PDA, 
and used what we found out to support evolving models and to drive up user satisfaction; this includes targeted ebook PDA rentals for "just in time" access to ebooks content to satisfy interlibrary loan requests (an increasingly common model in HE). It is feasible that more targeted use of PDA could benefit Westminster, but ongoing work would be needed to monitor use of patron selected titles, and provide management information comparing PDA titles against academic/library selected material to find a balance that works both for our users and for our budgets.

Meantime, we continue with advocacy to promote digital resources, and the benefits of our ebooks portfolio, ebook collections and new acquisitions to students and staff in order to optimise usage. We recognise the need to increase support for new students unfamiliar with the "user unfriendly" aggregator platforms, as most do not provide a satisfactory user experience;

\section{Ebook learning and teaching strategy}

In relation to the University's strategy for learning and teaching, Deans of Faculties and the Pro-Vice-Chancellor for Teaching and Learning are involved with the university's current Learning Futures initiative, including a strand on "transforming learning and teaching". This developmental work is based on the Community of Inquiry model (Garrison and Anderson 2011), which provides a coherent framework to underpin all the different strands of the Learning Futures programme. Of particular relevance to the library service are some of the key principles.

(a) A focus on the educational experience and higher-order skills, which puts the educational experience right at its heart. It places emphasis on critical thinking and reflection, but it also stresses the importance of the social dimension of learning. Work on Graduate Attributes, including digital and information literacy, will underpin this.

(b) A solid and realistic basis for integrating technology into higher education and promoting blended learning. The model recognises the potential of technology, but dismisses the use of technology for technology's sake. If technology is to be used, it must add value - it should provide a means through which learning is facilitated. This is true of the library's digital resources as well.

(c) Recognition of the enormous value of the face-to-face educational experience. Blended-learning approaches should not be viewed as replacing these experiences.

(d) A basis for the promotion of a blended-learning approach, which offers the potential to create a community of inquiry independent of time and location through the use of information and communication technologies. The power of blended learning is that it respects the advantages and preferences of face-to-face, whilst recognising the enormous 
strengths of online learning. Realising the potential of e-learning does not imply that traditional education is obsolete, rather that e-learning's capabilities can actively enhance traditional educational ideals. The educational rationale for blended learning is the ability of a blendedlearning design to engage participants in critical reflection and discourse by creating a flexible and sustainable community of inquiry. Blended-learning designs can extend time and tasks that sustain a community of inquiry beyond the limited frame of the traditional faceto-face classroom.

\section{Aligning services to strategy}

Our challenge is to align our services with the theoretical framework as it evolves. Meantime, I expect work to emerge within the Learning Futures initiative to explore user behaviour with students given the ongoing evolution in the use of digital resources, ebooks and changes to the supply model. Today, aggregators such as CourseSmart and VitalSource prefer conversations directly with academic colleagues to promote a 1 to 1 student textbook model, with associated class note sharing facilities, finding new ways to increase their market share by tailored cost negotiation based on full-time equivalent users/length of course, while bypassing the library as the traditional funder of such resources. This implies that libraries would not support a student-centric model which gives access to a set course book through the virtual learning environment (VLE), or direct via the publisher platform. Moreover, it implies that we do not want to engage with supporting access to resources after a student graduates as part of an institutional lifelong learning agenda. Such business models are challenging, as they expand the need to support content from more publishers on yet another dynamic platform. The library is usually better placed to manage the process including procurement, licensing and access management and to help users meet expectations of the experience whether through on- or off-campus access, and across a range of mobile devices.

\section{Use of ebooks}

A quick turnaround survey of taught course students via Blackboard around use of ebooks at the university in March 2014 showed that most respondents $(60 \%)$ used ebooks weekly, or at least monthly, with most use being related to textbooks and reference works (90\%) to help complete coursework assignments. Ease of use and access across multiple devices are considered essential, not just desirable. Anecdotally, ebook users utilise the content in short targeted bursts, and we know they use other resources including print books and content on other devices, at the same time. While it is difficult to compare the 
value of physical against virtual usage on such a small sample, these findings underline the digital shift and the importance of digital library activities to our users. Preliminary results from the 2014 LibQual survey at the university highlight again the message that students on taught courses need access to the "main texts and readings I need for my work" and make "electronic resources accessible from home or office" amongst their top requirements. While this is not a surprise, it underlines how we have to ensure we weave ebooks into our offering as a genuine way of improving the student experience, not as an add-on.

With regard to core texts in relation to learning and teaching, we are watching the current pilot for core text provision that the London Universities Purchasing Consortium (LUPC) is currently running with Queen Mary London. Phase 2 (from September 2014) will be opened up to a wider cohort of interested institutions and we are gauging faculty interest and funding. Some of our academics are also experimenting with WileyPlus fully integrated inside Blackboard for their modules.

\section{IT challenges}

Within our service we are exploiting access via the VLE (Blackboard), and have a project underway to bring in new reading-list software to further facilitate planning and budgeting. The reading-list software will offer new opportunities for the library to work with academic staff and students on managing lists, reducing out of date/out of print items previously listed, and positively acquiring alternative ebooks, subject to availability and pricing. For ease of deployment and to increase user engagement, it remains important to integrate access solutions into existing workflows and systems as much as possible. We use existing authentication systems to simplify access and to increase reliability and resilience (as an institution we use the Lightweight Directory Access Protocol (LDAP) internet standard) and we offer Shibboleth login where practical. There is new work under way in respect of institutional IT access and identity management, which we intend to help us exploit managed user groups' access more effectively. That said, for users, there are known, big problems to solve - the multiplicity of formats and platforms, the restrictions on use, the restrictions on using devices, formats and access routes they prefer, and the limited functionality and incompatibility with non-academic ebooks. Another aspect will be the "open" agenda - exploitation of Open Educational Resources (OER) as well as access to more OA ebooks as ways to manage cost and optimise impact.

I would add that Westminster has good support for visually impaired users, including sourcing of text files from publishers, and recent feedback has indicated that ebooks can be a viable offering. However, digital rights management (DRM) and the need to download specialist digital publishing software 
still present a barrier to usage, not least with a cost implication for users onand off-campus. Not all visually disadvantaged users wish to use only the text-to-speech function, and more industry development in partnership with organisations such as Jisc TechDis will be required to provide a more viable solution. We look forward to the development of more user-friendly alternatives, including digital watermarking.

\section{What the user wants}

In terms of the user's learning experience, it is important to take a more userbased approach and to remember why s/he needs the content in the first place or what "job" they are doing (e.g. to get an assignment done). Often (in an ebook context) we focus on the function of delivery online or ebook formats. What has passed into the sector's folk memory is the presentation by Joshua Harding, a second year medical student at Warwick Medical School, at the 2013 UKSG Conference who (politely) took publishers and librarians to task for simply not moving fast enough to give him what he wants. What he said he wanted (and wasn't getting without paying for it personally) was everything integrated in his personal iPad based "ecosystem"; this included:

- Intuitive navigation

- Interactive features - movies, animations, music, podcasts, slideshows, images, 3D models

- Search function through the entire book

- Highlighting text, making notes and sharing them

- Purchasing per chapter

- Free content updates

"From my limited perspective, much of what is wrong with the system comes down to the fact that publishers and libraries have to plan well in advance and make changes slowly... Students on the other hand are able to change direction quickly and easily. The problem exists because the market has changed so radically in the past few years that students have been able to adopt the new technologies well before the industry and libraries were able to make changes to support these students."

\section{An "above campus" shared service}

A second internal element is the requirement of greater efficiency and economy in the management of all professional and support services as the HE financial environment shifts and reshapes. Ebook management requires a

\footnotetext{
${ }^{5}$ http://www.slideshare.net/UKSG/0930-harding
} 
heavy investment in staffing (time and skills sets) in every HE institution (HEI), as ebook procurement, metadata, licensing and accessibility are (and are increasingly) complex. As a member of the Society of College, National and University Libraries (SCONUL) Shared and Collaborative Services Strategy Group, I have been an active supporter of the development of $\mathrm{KB}^{6}{ }^{6}$ as a centralised, shared, above-campus knowledge base of data useful to electronic resources management (ERM) at institutional level, recognising the potential for these activities to be integrated into a shared service "above campus" based on automated and integrated workflows to avoid single points of failure. As of May 2014, KB+ has data from over 170 institutions with some 550 registered users of the service.

Most recently, as part of the Jisc co-design programme, the $\mathrm{KB}+$ project team, supported by the University of Huddersfield, undertook a consultation exercise to identify and assess the pain points relating to ebooks ${ }^{7}$ and postcancellation access ${ }^{8}$ as reported by academic libraries and their users.

Drawn from over 500 delegate submissions across a range of HE libraries, a total of 47 pain points were identified by librarians and further validated through a voting process during the study. It grouped problems into four categories: ones that that seem intractable (too big/too complex/out of our control); ones we can solve locally ourselves; those requiring local resolution, but which would benefit from above-campus support; and those that can only be tackled through above-campus or community action (e.g. through a shared service). Each of the top 12 pain points (25\%) received majority endorsement (over 66\%) for "above campus" support as a solution. These "dirty dozen" are recognisable by any library service director:

- Improve e-book compatibility with mobile devices

- Compatibility with accessibility software

- Share knowledge on procurement issues

- Standardise and simplify licensing

- Adopt a community approach to negotiating with publishers

- Single ebook acquisition and discovery service including pricing and models

- Better usage statistics - Journal Usage Statistics Portal (JUSP) for ebooks

- Normalise ebook ISBNs

- Provide continuing and archival access

- Preservation of DRM-free content

- Finding out what ebooks are available

- Share techniques for local statistics collection

\footnotetext{
${ }^{6}$ http://www.kbplus.ac.uk/kbplus/about

7 http://knowledgebaseplus.wordpress.com/ebooks-co-design-project/ebooks-full-report/

8 http://knowledgebaseplus.wordpress.com/pca-co-design-project/pca-full-report/
} 
While this list will come as no surprise, it is disappointing that publishing models and services as they exist today cannot help us to solve them.

\section{External drivers - a time of intense scrutiny}

Today the digital future of the book in the HE environment is the focus of intense scrutiny; this is important for all aspects of HE services supporting learning, teaching and research. Four important initiatives - by funders, by Jisc and other sector bodies and library services - are currently taking place which are worthy of special mention here as their outcomes can help solve some of the wider, intractable issues:

(a) The Jisc pilot co-design project on a national monograph strategy: its report, expected be published in Spring 2014, forms the final output from the first phase of a project which ran from July 2013 until January 2014 in collaboration with SCONUL and Research Libraries UK (RLUK) ${ }^{9}$. Part of its work has been around identifying the need for an infrastructure that can give access to both digital and hard-copy monographs via a stable business model with appropriate collaborative approaches to licensing and digitisation, and which would offer innovative approaches to publishing and new formats.

(b) OAPEN (Open Access Publishing in European Networks) ${ }^{10}$ : this primarily explores open access monograph business models in the humanities and social sciences, and the goal is to foster the creation of new content by developing future-orientated publishing solutions, including an open access library for peer reviewed books;

(c) The Higher Education Funding Council for England (HEFCE) expert reference group on Monographs and Open Access Publishing ${ }^{11}$ has been set up to develop increased understanding about the challenges and opportunities for open-access monograph publishing.

(d) The Arts and Humanities Research Council (AHRC) and the British Library have launched a two-year research project on the academic book of the future in the context of OA publishing and continuing digital change. ${ }^{12}$

These developments are against the background of frustration with the publishing model, its unsustainable mixture of formats and platforms and changes in the behaviour and expectations of students and other users. As

\footnotetext{
${ }^{9}$ http://monographs.jiscinvolve.org/wp/

${ }^{10}$ http://oapen-uk.jiscebooks.org/oapen/

${ }_{11}$ http://www.hefce.ac.uk/whatwedo/rsrch/rinfrastruct/oa/monographs/

12 http://www.ahrc.ac.uk/News-and-Events/News/Pages/The-Academic-Book-of-the-Future. aspx
} 
a sector, we are also experiencing another shift with publishers withdrawing textbooks from unlimited concurrent users and imposing limits. For all HE library directors, the holy grail remains publishing models that are sustainable and affordable.

\section{University publishing initiatives}

Today some HEIs are considering moving to become e-textbook creators as well as OA publishers. In March 2014, Jisc Collections invited UK HE institutions to participate in a three-year national project to explore the viability of institutions becoming e-textbook publishers ${ }^{13}$. The project will assess the following question: "Will the institution as e-textbook creator help students by providing a more affordable higher education, and promote a better, more sustainable information environment for libraries, students and faculty?" The term "e-textbook" is defined by Jisc Collections as: "a coherent package of learning materials in electronic form that is fundamental to a course of study at an Further Education College (FEC) or HEI" and which should be reusable, accessible, interoperable, and durable. Moreover, as learning objects e-textbooks must be capable of supporting the different activities and interactions that teachers, or learning designers, might use or encourage; be capable of integration into a range of virtual/managed learning environments; support multiple uses through multiple devices in multiple environments (including offline where appropriate); be benchmarkable for functionality and range of learning materials against the products of accepted commercial market leaders; and be fully hospitable to FECs'/HEIs' requirements in terms of accessibility, such as supporting text-to-speech, magnification, choice of colours for backgrounds and texts, and adhere to recognised standards. An accompanying landscape report by David Ball sets out the current environment and issues in rich detail.

In Scotland, the Scottish Higher Education Digital Library (SHEDL) aims through collaboration and combined purchasing power to achieve a shared digital library with easier access to online content to support research and learning and teaching. Its HE libraries ebook purchase tender work has highlighted to the library community that the publishers they use are making available few (if any) of the textbooks that they want to be able to purchase collectively in their ebook packages; consequently they are all grappling individually with challenging and expensive data rights management when they wish to obtain textbook material. Given there is a common interest in addressing this, the libraries are discussing how they can cooperate to share the costs of e-textbook publishing, and then release the material by OA. SHEDL is to

\footnotetext{
${ }^{13}$ http://www.jisc-collections.ac.uk/News/Institution-as-e-textbook-publisher-call-for-particiation/
} 
explore this approach by commissioning a set of pilot e-textbooks to support undergraduate and postgraduate study in certain fields of suitable significant interest across the SHEDL partners (e.g. Scottish law, devolution and government, offshore renewable energy, science and policy, renewable energy in maritime high-latitude environments, and Gaelic language).

While OA methodologies are likely to provide a more cost-effective route to the provision of textbook information, the challenge of funding the research, authoring, publishing and maintenance costs remains. The SHEDL business model is being developed and they estimate the likely timetable for a full e-textbook production may take two years or even longer. The process will most likely invite competitive bids for the overall subject and individual chapter coverage, and they estimate that the costs of producing an e-textbook on a reasonably defined subject area may be in the region of $£ 3000$ to $£ 5000$, including an author royalty of $£ 500$ to $£ 1000$. It is anticipated they would seek to use of variants of models used by e.g. Knowledge Unlatched, Open Library of the Humanities, Jisc Collections and Ubiquity Press. Publishing models that are sustainable and affordable will be a paramount consideration.

At the time of writing, the University of Westminster is establishing the University of Westminster Press in partnership with Ubiquity Press for some of these same reasons. It will provide a university-branded dissemination channel for high-quality research, for the production of online articles and journals, digital and print-on-demand monographs, conference proceedings and other forms of peer-reviewed research output, increasing the profile and standing of Westminster's research, providing an income generation channel and supporting our research engagement and excellence missions. A Westminster thesis series is also under consideration. It is to be hoped that we can also move into the e-textbook publishing space over time. The press will provide us with an online publishing platform and service supported by international peer-review networks, and will demonstrate the university's commitment to the OA agenda and facilitate high quality publications (in particular from early career researchers).

This will contribute to the disruption of conventional commercial models of scholarly communication and advance the OA agenda, addressing issues prevalent in the current commercial model, by significantly reducing the costs of publishing and addressing problems such as loss of copyright. The Ubiquity Press is based on a collaborative model (Ubiquity Partners Network) involving a network of peer review, and a governance structure involving participation from members of the Ubiquity Partners Network. Our press will operate under the oversight of a board with editorial and governance responsibilities.

Standards of editorial practice will be benchmarked to those of established and reputed academic publishers. Peer review is facilitated through Ubiquity's partner network of expertise. In the initial three-year term, the aim is to 
publish three journals and five books. In the initial stages, it is anticipated that publications will be solely from Westminster, but further development is planned to enable publication of externally produced outputs. The publishing model is based primarily on a Gold OA approach, with article processing charges and book processing charges. The key difference from standard commercial models is that the charging system is designed to be affordable and sustainable, and charges will be significantly lower than those of commercial operators. The details of pricing are currently under consideration by the university. The inception of the university press is an important development for the university in the context of OA publishing, including the new REF OA requirements. We are seeking the active engagement of faculty research leaders and colleagues currently involved in academic publishing.

\section{Closing comments}

There are continuing and even increasing concerns about the processes involved in the management and delivery of ebooks, relating both to library functions and to the end-user experience. As the core texts model(s) and OA/ OER resources mature, and student-as-consumer expectations grow, provision of core texts will not be an easy challenge. Varied and mixed economies are currently being experimented with, including text provision (print or electronic), text plus device provision, tokens towards text cost (used on Amazon, aggregator platform or on-site bookshop) and direct student purchase. The potential for change is still "around the corner", but the complexity of the issues and the seemingly intractable nature of the problems continue to exercise service directors, our staff and users.

It is likely that, with the spotlight now on the future of the monograph, the distinctiveness of an institutional ebook support offering will become a more important issue for institutions across HE. The drivers include content cost, current publishing models, active promotion of OA and even cohort size. It will interesting to see where the move to "blended content" takes us as libraries begin to exploit both our paid-for and open (OA/OER) content more systematically. That said, a large part of the innovation and "competition" is taking a very consumerist approach. Much of what service directors (and many scholarly publishers too) talk about is, naturally enough, from the supplier point of view (and this includes the library as supplier).

As service directors, we must always try to shift more towards a user perspective and constantly ask ourselves "is this going to change the user's learning experience?" What unites us all at a local level is the customer-centric drive to provide content to support both our current student cohort and lifelong learning. The big question is how and when we can all reimagine content so that the norm for ebooks is that they have become true "natively digital" in origin, with imaginative built-in interactivity features and multimedia 
elements, including video and 3D objects, to enhance the learning experience, rather than being a more or less faithful electronic version of a traditional print textbook with all the drawbacks inherent in that.

\section{Reference}

Garrison, D. R. and Anderson, T. (2011) E-learning in the 21st century: a framework for research and practice (2nd edition). London: Routledge/ Falmer. 